\title{
Typology of the Regions with the Account of Level of Influence of Infrastructure Facilities on the Structure of Economic Areas
}

\author{
N. G. Bagautdinova ${ }^{1}$, G. N. Hadiullina ${ }^{1}$, A. V. Sarkin ${ }^{1} \&$ O. V. Pratchenko ${ }^{1}$ \\ ${ }^{1}$ Kazan (Volga region) Federal University, Russian Federation \\ Correspondence: N. G. Bagautdinova, Kremlevskaya str. 18, Kazan, 420008, Russian Federation. E-mail: \\ science-kfu@mail.ru
}

Received: June 6, 2014 Accepted: July 14, 2014 Online Published: September 28, 2014

doi:10.5539/ass.v10n20p57 URL: http://dx.doi.org/10.5539/ass.v10n20p57

\begin{abstract}
The aim of the work is to develop methodological approach for estimation of condition of infrastructural complex as "growing point" of regional economic area with the account of types of transactional cooperation of objects of infrastructure. In the process of achievement of the aim the following transactions were singled out: the main, auxiliary, servicing transactions with participation of infrastructural complex, and transactions that prevent the realization of the main ones, and it is the basis for typology of regions with the account of level of influence of infrastructure facilities on the structure of economic area, condition and dynamics of development of the main meso-economic indicators.
\end{abstract}

Keywords: regional economic space, infrastructural complex as growing point, regional management, main, servicing and auxiliary transactions, gross regional product

\section{Introduction}

Formation of a stable trend of multipolar development of Russian economic space was confirmed in the period of crisis of 2008-2009, which led to the deterioration of the situation of regions characterized by a predominance in gross regional product (GRP) of products of traditional manufacturing industry, which became the result of low competitiveness of enterprises, with simultaneous appearance of investment-attractive subjects of the Federation focused on import of hi-tech. Alternative character of principles, on which the models of polarized and leveling regional development are based, does not exclude the presence of common element as their part, and recognition of effective infrastructure as the significant factor and the result of linear dynamics is presented as this element. In the section rating of the World Bank the Russian Federation (RF) is on the 48th place in the world in terms of availability and quality of transport infrastructure, in terms of quality of railway infrastructure-33rd place, in terms of quality of road-transport infrastructure-111th place, in terms of quality of infrastructure of air and water ports-87th and 82nd places respectively (Safiullin, 2014). Nature of the spatial distribution of resources determines low energetic efficiency of the Russian economy with a high proportion of capital investment of total GDP (5\% of GDP at $1.5 \%$ of global average). Social and institutional infrastructure still serves as a deterrent factor of economic growth. Need to rethink domestic experience of infrastructure management and selection of the most effective directions of its development in the context of realization of the model of polarized development of national economic space, ineffectiveness of existing mechanisms of cooperation of infrastructure complex business entities with public authorities and the community of the area-all this predetermined the choice of the research topic, its importance in theoretical and practical aspects. (Akhtyamova, 2013)

Assessment of the extent of scientific development of the problem says that at present issues of spatial development of territorial entities are in the center of attention focus of scientists and experts. Spatial economic equilibrium model is presented in the works of A. Predel and G. Vaygman. The models of economic growth were developed in the works of P. Douglas, C. Cobb, R. Solow, E. Phelps and others. Factors and directions of spatial optimization of economic performance at the micro-level were reflected in the models of spatial interactions which use parametric time as an attributive element (Bagautdinova, 2012). However, analysis of the scientific literature shows that the process of restructuring of the economic space of the region under the influence of changes in the infrastructure complex is studied insufficiently. It determined the content of the purpose and objectives of the work, as well as the main directions of research. 


\section{Methodology}

Concepts and hypotheses, well founded and presented in modern economic literature, which are devoted to the principles of regional management, geopolitics, distribution of productive forces, logistics, systems theory, economic and mathematical methods, organization theory, became the theoretical and methodological basis of the study.

Systematic and historical approaches, prospective and retrospective analysis, methods of mathematical statistics and methods of economic and mathematical modeling were used to solve sub-problems of the research. (Bagautdinova, 2013) The systematic approach to the problem was used to develop the major issues of economic forecasting, and it allowed to provide comprehensive research and to identify the main ways of development and improvement of the efficiency of management at the meso-level.

\section{Results}

Differences in the rate of change of indicators of the selected types of transactions cause differences in condition and directions of development of economic space, which is the basis for development of classification of regions. Assumption concerning possibility of considering primary and secondary transactions as unified in their functional essence and which differ in forms and scope of influence made it possible to identify 6 types of Russian regions which are characterized by the following ratio of development rates of distinguished groups of transactions.

\section{Discussion}

Each element of infrastructure is characterized by its own set of parameters (power, capacity, etc.), condition and dynamics of which determines the characteristics of infrastructural capacity of the region, which, in turn has, influences the investment attractiveness of the region and its ability to ensure effects of economy from the range of activity, localization economy, sectorial and urbanization economy. At the same time, lack of the common methodological approach to the definition of essence of the infrastructural complex is the reason of lack of an integral indicator which reflects the extent of its influence on the level of efficiency of the spatial organization of the regional economy (Ohmae, 1995); (Richardson, 1973).

In accordance with the author's definition of economic space, the following transactions are singled out as parts of the flow of transactions: main, auxiliary, serving transactions and transactions that prevent the realization of the main ones (North, 1955). Calculation of the composite indicator which reflects the condition of the entire set of transactions involving objects of infrastructure, allows making the case for effective regulatory enforcement actions from the side of state run public authorities in order to improve the efficiency of the spatial organization of the regional economy. In this connection, it is possible to use the block structure of the system of indicators that reflect condition and dynamics of the types of transactions.

The structure of indicators characterizing the main transactions involving infrastructure complex includes the following indicators: balanced financial result of activity of enterprises of the infrastructure; gross regional product per capita; the ratio of investment for development of infrastructure in the region to the gross added value and GRP; level of availability of infrastructure facilities per capita in the area of infrastructure (housing, roads, etc.); Human Development Index as a combined state indicator of general living environmental conditions of the population of the region, etc. The structure of indicators characterizing auxiliary transactions involving infrastructure complex includes the following indicators: indicators that reflect compliance of the level and structure of infrastructure to personal and productive needs of the local community and business entities of the area, etc. The structure of indicators characterizing serving transactions involving infrastructure complex includes the following indicators: indicators of the level of performance efficiency of infrastructure management at the national and regional levels, etc. (Friedmann, 1977); (Hirschman, 1958); (Kanter, 1995); (Myrdal, 1957).

The structure of indicators characterizing transactions involving complex infrastructure interfering the realization of the main ones, includes the following indicators: the amount and growth rate of transaction costs (Townroe, 1979). This system of indicators allows to evaluate the effectiveness of management of infrastructural complex in the region, taking into account the level of process details, and to specify the evaluation by groups of subjects of infrastructure activities. For example, in making an assessment of the transport complex of the region the following indicators characterizing the main transactions, should be included: indicators of load capacity of GRP, freight and passenger transport, length and delivery capacity of transport networks, highways density ratio, net profit ratio of current activity, coefficient of depreciation of fixed assets; the following indicators should be included into the list of indicators which characterize auxiliary transactions: indicators of public transport services, indicators of the transport companies; the following indicators should be included into the list of 
indicators which characterize serving transactions: indicators of managerial effectiveness, investment attractiveness, relative share of social burden in the transportation rate, coefficients of state support of development. The following indicators should be included into the list of indicators which characterize transactions involving the transport complex, which interfere the realization of the main ones: transport accident rates, durability, expected-on time of serviceability and technical security, etc. (Friedman, 1978).

This study allowed identifying 6 types of regions which are characterized by the following proportion of rates of development of the distinguished groups of transactions:

I group: regions characterized by stable innovation-oriented and socially-oriented growth, which is caused by predominance of the growth rates of indicators of the main and auxiliary transactions involving infrastructure facilities over the growth rate of indicators which serve transactions, and transactions that prevent realization of the main ones (there are no such regions in the Russian Federation). This proportion of types of transactions determines presence of support areas and zones of advanced economic growth that provides a high level of structuring and self-organization of economic space.

II group: regions characterized by stable growth, which is caused by predominance of the growth rates of indicators of the main and auxiliary transactions involving infrastructure facilities over the growth rate of indicators of transactions that prevent realization of the main ones. At that the growth rate of serving transactions is lower than the growth rate of indicators of the main and auxiliary transactions, as well as of the growth rate of indicators that interfere realization of the main ones (cities of Moscow, St. Petersburg, Moscow region, Republic of Tatarstan, Komi, Sakha (Yakutia), Sakhalin region, Tyumen region, Nizhny Novgorod region, Novosibirsk region, Rostov region, Samara region, Sverdlovsk region). This ratio of types of transactions determines presence of support areas and zones of advanced economic growth that provides a relatively high level of structuring and self-organization of economic space.

III group: regions characterized by unstable growth, which is caused by predominance of the growth rates of indicators of servicing transactions involving infrastructure facilities over the growth rate of indicators of the main and auxiliary transactions, as well as over the growth rate of transactions that prevent realization of the main ones (Volgograd, Irkutsk, Leningrad, Lipetsk, Novgorod, Omsk, Chelyabinsk, Yaroslavl regions). This ratio of types of transactions determines formation of "growing points" that ensures average level of structuring and self-organization of economic space.

IV group: regions characterized by unstable decline, which is caused by predominance of the growth rates of indicators of servicing transactions involving infrastructure facilities over the growth rate of indicators that prevent realization of the main ones, as well as over the growth rate of indicators of the main and auxiliary transactions (Republic of Bashkortostan, Krasnoyarsk region, Perm region, Belgorod region, Kemerovo region, Murmansk region, Tomsk region). This ratio of types of transactions determines the start of formation of some "growing points" that ensures low level of structuring and self-organization of economic space.

V group: regions characterized by unstable decline, which is caused by predominance of the growth rates of indicators of transactions that prevent realization of the main ones, involving infrastructure facilities, over the growth rate of indicators of the main and auxiliary transactions, as well as over the growth rate of indicators of servicing transactions (Republic of Karelia, Khakassia, Udmurtia, Buryatia, Mari El, Mordovia, Chuvashia, Primorsky region, Khabarovsk region, Arkhangelsk, Vladimirovskaya, Ivanovo, Kaliningrad, Kaluga, Kostroma, Ryazan, Smolensk, Tver, Tula region, etc.). This ratio of types of transactions determines absence of "growing points" that ensures homogeneity of economic space and low level of its self-organization.

VI group: regions characterized by stable decline, which is caused by predominance of the growth rates of indicators of transactions that prevent realization of the main ones, involving infrastructure facilities, over the growth rate of indicators of servicing transactions, as well as over the growth rate of indicators of the main and auxiliary transactions (Republic of Adygea, Altai, Dagestan, Ingushetia, Kabardino-Balkaria, Kalmykia, Zabaikalsky region, Amur, Magadan region, Chukotka Autonomous region, etc.). This ratio of types of transactions determines absence of "growing points" that ensures homogeneity of economic space and extremely low level of its self-organization.

The presented a typology of regions is the basis for the development and grounds for the development strategy, the implementation of which provides increase of efficiency of the spatial organization of the regional economy by using its infrastructure capacity.

Forecast of dynamics of the gross regional product of the Republic of Tatarstan for 2015-2019 for three scenarios, adjusted with account of the extrapolation results of tendencies of changes of GRP with the account of cargo 
intensity parameter, obtained in the process of the research, is shown in Figure 1 (Russia by the Numbers, 2013).

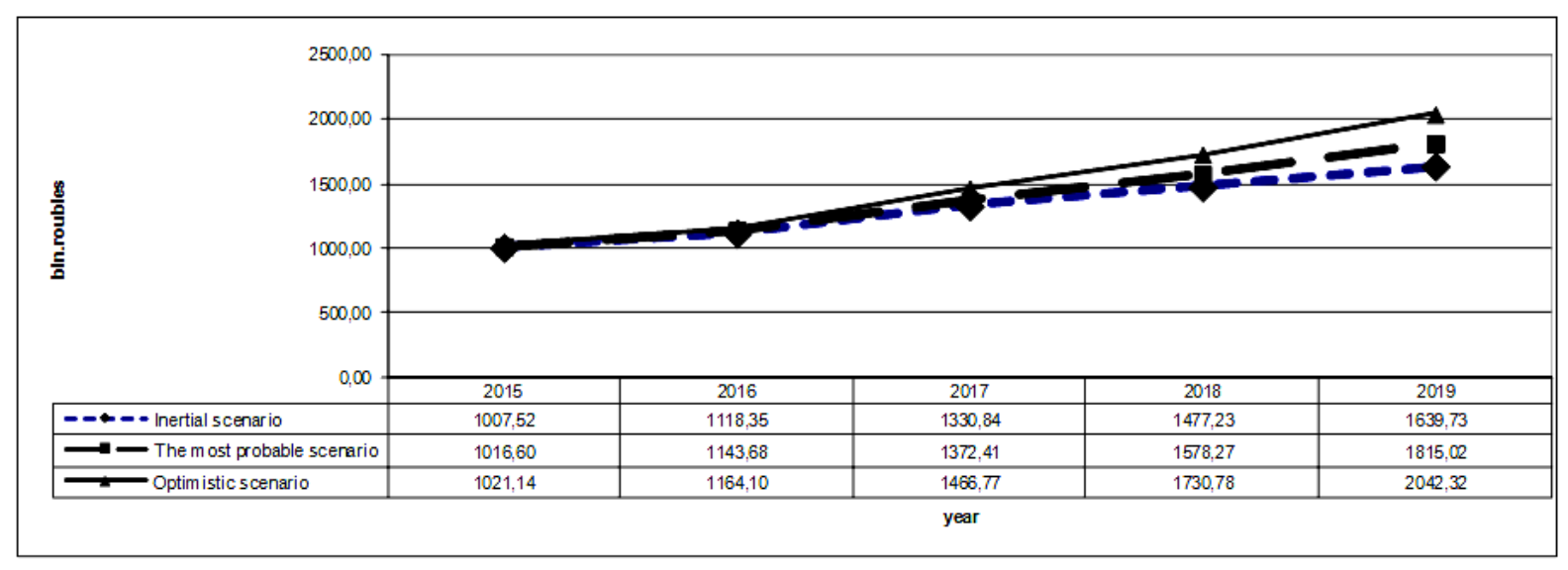

Figure 1. Dynamics of GRP of the Republic of Tatarstan of development scenarios of the region for 2010-2015 (forecast)

Forecast of the results of introduction of the methods and mechanisms of regional management offered in the work was implemented on the basis of the following scenarios of development of the Republic of Tatarstan:

1) Inertial scenario, in the frames of which the proposed instruments and mechanisms are not introduced, and the level of cargo capacity of gross regional product will vary according to the prevailing tendencies.

2) The most probable scenario, according to which the proposed instruments and mechanisms are partially introduced into the practice of regional management (efficiency of their application is $60 \%$ from the target one), and the level of GRP cargo capacity decreases in comparison with the inertial scenario with growth of returns from cargo transportation.

3) Optimistic scenario, in the frames of which the proposed instruments and mechanisms are introduced into the practice of regional management with $90 \%$ efficiency and the level of GRP cargo capacity falls with priority rates in comparison with the inertial scenario with growth of returns from cargo transportation.

As it is seen from the above data, the implementation of the proposed methods and mechanisms is economically reasonable in the medium-term period, while by the end of the five-year period with implementation of the most probable scenario the GRP growth rate will be $10.7 \%$ in comparison with the inertial variant of development of the region

\section{Conclusion}

Relevance of the choice of the model of multipolar development of national economics by federal state run authorities is determined by several factors, among which the most important are the following: significant amount of natural resources requested by the world economy, which are localized in a relatively small number of regions; the inland geographical position of the vast majority of subjects of the Federation that causes high level of transport costs; paucity of large urban agglomerations and low population density, preventing the diffusion of innovations in space; decrease of quality of human capital and polarization of the settlement, limiting the possibility of creation of "growth points" and support areas; low efficiency of the institutional environment, stimulating multi-vector spatial development of the national economy and its separate territorial entities.

Effect of the above-mentioned factors-with underdeveloped transport, energy, industrial and social infrastructure-results in high non-uniformity of the Russian economic space, which is reflected in the dynamics of meso-economic indicators.

\section{Summary}

The region has a number of key competencies which are interpreted as a set of formation and development of specific, formidably simulated agents of transactions of sources of sustainable competitive advantages. Unlike the other agents of transactions the region has not only the factors that provide temporary competitive advantages, but also the factors that ensure stable competitive advantages, which are controlled, formidably simulated by other agents' parameters of internal environment. Development of the latter ensures the formation the area of simultaneous allocation of economic and social value by business entities. 


\section{References}

Akhtyamova, N., Bagautdinova, N., \& Novenkova, A. (2013). Conceptual Features of Management Models in the West and East. World Applied Sciences, 27(13), 10-14.

Bagautdinova, N., Gafurov, I., Kalenskaya, N., \& Novenkova, A. (2012). The regional development strategy based on territorial marketing (The Case of Russia). World Applied Sciences Journal, 18, 179-184.

Bagautdinova, N., Murtazina, G., Fazlieva, E., \& Naida, A. (2013). Improvement of the regional management system using the labor potential index. World Applied Sciences, 27(1), 107-111.

Friedmann, J., \& Alonso, W. (1978). Regional policy: Readings in Theory and Applications. MIT Press, England.

Friedmann, J., \& Weaver, C. (1979). Territory and function. The evolution of regional planning. Edward Arnold.

Hirschman, A. O. (1958). The strategy of economic development. New Haven: Yale University Press.

Kanter, R. M. (1995). World class: Thriving locally in the global economy. New York: Simon \& Schuster.

Myrdal, G. (1957). Economic theory and underdeveloped regions. London: Gerald Duckworth.

North, D. (1955). Location theory and regional economic growth. Journal of political economy, 63(3), 243. http://dx.doi.org/10.1086/257668

Ohmae, K. (1995). The end of the nation state: The rise of regional economics. London: Harper-Collins.

Richardson, H. W. (1973). Regional growth theory. London: Macmillan.

Safiullin, L., Gafurov, I., Shaidullin, R., \& Safiullin, N. (2014). Socio-economic development of the region and its historical and cultural heritage. Life Science, 11(6s), 400-404.

Safiullin, L., Novenkova, A., Safiulli, N., \& Ismagilova, G. (2014). Prospects of small business in Tatarstan. Life Science Journal, 11(6s), 396-399.

Townroe, P. M. (1979). Location factors in the decentralization of industry: A survey of metropolitan Sao Paulo, Brazil. Washington, D.C., U.S.A.: World Bank.

\section{Copyrights}

Copyright for this article is retained by the author(s), with first publication rights granted to the journal.

This is an open-access article distributed under the terms and conditions of the Creative Commons Attribution license (http://creativecommons.org/licenses/by/3.0/). 